\title{
Efficacy of Spironolactone Treatment in Murine Models of Cutaneous and Visceral Leishmaniasis
}

\author{
Valter Viana Andrade-Neto ${ }^{1}$, Juliana da Silva Pacheco ${ }^{1,2}$, Job Domingos Inácio ${ }^{1}$, \\ Elmo Eduardo Almeida-Amaral ${ }^{1}$, Eduardo Caio Torres-Santos ${ }^{1 *}$ and \\ Edezio Ferreira Cunha-Junior ${ }^{1,3 *}$
}

${ }^{1}$ Laboratorio de Bioquímica de Tripanosomatídeos, Instituto Oswaldo Cruz, Fundação Oswaldo Cruz, Rio de Janeiro, Brazil, ${ }^{2}$ Division of Biological Chemistry and Drug Discovery, School of Life Sciences, University of Dundee, Dundee, United Kingdom, ${ }^{3}$ Laboratório de Imunoparasitologia, Unidade Integrada de Pesquisa em Produtos Bioativos e Biociências, Universidade Federal do Rio de Janeiro, Campus UFRJ-Macaé, Macaé, Brazil

Translational studies involving the reuse and association of drugs are approaches that can result in higher success rates in the discovery and development of drugs for serious public health problems, including leishmaniasis. If we consider the number of pathogenic species in relation to therapeutic options, this arsenal is still small, and each drug possesses a disadvantage in terms of toxicity, efficacy, price, or treatment regimen. In the search for new drugs, we performed a drug screening of $L$. amazonensis promastigotes and intracellular amastigotes of fifty available drugs belonging to several classes according to their pharmacophoric group. Spironolactone, a potassium-sparing diuretic, proved to be the most promising drug candidate. After demonstrating the in vitro antileishmanial activity, we evaluated the efficacy on a murine experimental model with $L$. amazonensis and $L$. infantum. The treatment controlled the cutaneous lesion and reduced the parasite burden of $L$. amazonensis significantly, as effectively as meglumine antimoniate. The treatment of experimental visceral leishmaniasis was effective in reducing the parasite load on the main affected organs (spleen and liver) via high doses of spironolactone. The association between spironolactone and meglumine antimoniate promoted better control of the parasite load in the spleen and liver compared to the group treated with meglumine antimoniate alone. These results reveal a possible benefit of the concomitant use of spironolactone and meglumine antimoniate that should be studied more in depth for the future possibility of repositioning for leishmaniasis co-therapy.

Keywords: spironolactone, drug repositioning, leishmania, visceral leishmaniasis, pentavalent antimonial

\section{INTRODUCTION}

In 2018, among the 200 countries or territories that sent reports to the World Health Organization, 88 were considered endemic for cutaneous leishmaniasis (CL) and 78 were considered endemic for visceral leishmaniasis (VL) (WHO Control of Neglected Tropical Diseases, 2020). It is considered the third most common parasitic disease, after schistosomiasis and malaria, based on morbidity and disability-adjusted life years (DALYs) (GBD 2015 DALYs and HALE Collaborators, 2016). Because of its widespread occurrence, predominantly in the poorest social strata, leishmaniasis is among the most 
neglected diseases, with very limited investment in diagnosis, treatment, and control (Sunyoto et al., 2019).

Currently, leishmaniasis is treated with a small arsenal of drugs, including pentavalent antimonials, amphotericin B deoxycholate, lipid formulations of amphotericin $B$, miltefosine, and paromomycin, all of which have disadvantages in terms of toxicity, efficacy, price, or treatment regimen (Agil, 2015). The development of cheaper, safer, and orally available drugs is urgently needed. One way to accelerate this process is the well-known strategy of "old drug, new use research." Drugs that are currently on the market have already undergone pharmacokinetic and toxicity testing and have been proven to be clinically safe, thus obviating the problematic testing bottleneck of the drug discovery pipeline. One recent example of the successful use of this approach is the demonstration of fexinidazole's leishmanicidal activity in vitro and in vivo against Leishmania infantum, $L$. amazonensis, and $L$. braziliensis (Wyllie et al., 2012; de Morais-Teixeira et al., 2019).

Moreover, a recent revision paper published by our group demonstrated that several studies aiming at repurposing drugs for leishmaniasis have been carried out, comprising around 83 drugs (Andrade-Neto et al., 2018). Our group also performed a screening of fifty available drugs belonging to several pharmacological categories; of these, spironolactone (Figure 1), a potassium-sparing diuretic that acts as an aldosterone receptor antagonist, proved to be the most promising drug candidate. Spironolactone was developed in the 1950s, and it is licensed for the treatment of hypertension, heart failure, hypokalemia, and other morbidities (Wile, 2012). In this study, we describe the leishmanicidal activity of spironolactone in vitro and its efficacy in treatment alone or in co-therapy with the meglumine antimoniate of experimental cutaneous and visceral leishmaniasis.

\section{MATERIALS AND METHODS}

\section{Parasite}

Promastigotes of Leishmania amazonensis (strain MHOM/BR/ 77/LTB 0016) and Leishmania infantum (strain MHOM/MA/67/ ITMAP-263) were maintained at $26^{\circ} \mathrm{C}$ in Schneider's insect

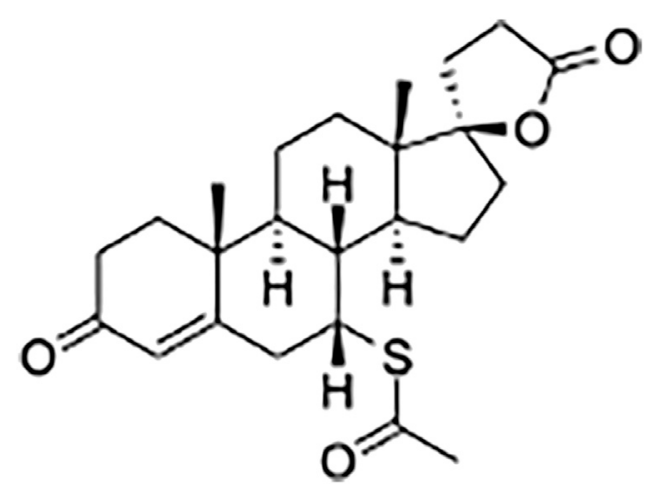

FIGURE 1 | Structure of spironolactone. medium (Sigma-Aldrich, St Louis, MO, United States) with $10 \%$ or $20 \%$ serum, respectively, with $100 \mu \mathrm{g} / \mathrm{ml}$ streptomycin and $100 \mathrm{U} / \mathrm{mL}$ penicillin until the fifth passage. Afterward, old cultures were discarded, and fresh parasites were obtained from infected $\mathrm{BALB} / \mathrm{c}$ mice.

\section{In vitro Studies}

\section{Antipromastigote Activity}

Promastigotes of L. amazonensis and L. infantum at $1 \times 10^{6}$ cells/ $\mathrm{ml}$ were incubated with spironolactone $(0-50 \mu \mathrm{M})$ or canrenoate $(0-128 \mu \mathrm{M})$ for $72 \mathrm{~h}$ at $26^{\circ} \mathrm{C}$. The assays were performed in triplicate in 96-well plates (Costar, New York, United States). Inhibition parasite growth was assessed by a fluorescent assay, Resazurin (Sigma-Aldrich) (Faiões et al., 2018). Briefly, $50 \mu \mathrm{M}$ of resazurin was added per well, and then the samples were incubated for an additional $2 \mathrm{~h}$. The fluorescence was measured using a Spectra Max GEMINI XPS spectrofluorometer (Molecular Devices, Silicon Valley, United States) at excitation and emission wavelengths of 560 and $590 \mathrm{~nm}$, respectively. The concentration effect curve was fitted for antipromastigote testing via nonlinear regression using Graph Pad Prism 7.0. Finally, the $\mathrm{IC}_{50}$ value was determined.

\section{Antiamastigote activity}

Resident macrophages from BALB/c mice were obtained by peritoneal lavage with $5 \mathrm{ml}$ of cold RPMI medium (SigmaAldrich). The cell suspension was adjusted to a $2 \times 10^{6} / \mathrm{ml}$ concentration and plated in LAB-TEK chambers (Nunc). After $1 \mathrm{~h}$, the cultures were washed with phosphate-buffered saline (PBS) at $37^{\circ} \mathrm{C}$ to remove non-adherent cells. The remaining cells were incubated at $37^{\circ} \mathrm{C} / 5 \% \quad \mathrm{CO}_{2}$ with promastigotes of $L$. amazonensis at a ratio of 3:1 or L. infantum at a ratio of 5:1. After $3 \mathrm{~h}$, the chambers were rewashed to remove free parasites. The monolayers were incubated with spironolactone $(0,2.5,5.0$, and $10.0 \mu \mathrm{M})$ or canrenoate $(0,2.0,4.0,8.0$, and $16 \mu \mathrm{M})$ for $72 \mathrm{~h}$ at $37^{\circ} \mathrm{C} / 5 \% \mathrm{CO}_{2}$. The antiamastigote activity was evaluated microscopically after staining the chambers with the Instant Prov hematological dye system (Newprov, Curitiba, Brazil); at least 100 macrophages were counted per sample. The results were expressed as the infection index (IF) using the following formula: IF $=\%$ infected cells $\mathrm{X}$ (number of amastigotes/total macrophages). The concentration effect curve was fitted for the antiamastigote test via nonlinear regression using Graph $\mathrm{Pad}$ Prism 7.0, and the $\mathrm{IC}_{50}$ value was determined.

\section{Cytotoxicity in Murine Macrophages}

Mouse peritoneal macrophages in 96-well plates were treated with spironolactone and canrenoate $(16-256 \mu \mathrm{M})$ for $72 \mathrm{~h}$ at $37^{\circ} \mathrm{C} / 5 \% \quad \mathrm{CO}_{2}$. After removing the supernatant, viable cells were quantified by adding resazurin in phosphate buffer saline (PBS), a final concentration of $50 \mu \mathrm{M}$, and then the samples were incubated for an additional $2 \mathrm{~h}$. The fluorescence was measured using a Spectra Max GEMINI XPS spectrofluorometer (Molecular Devices, Silicon Valley, United States) at excitation and emission wavelengths of 560 and $590 \mathrm{~nm}$, respectively. The percentage of viable cells was calculated relative to the control cells. The cytotoxic concentrations lethal to $50 \%$ of the cells 
$\left(\mathrm{CC}_{50}\right)$ were obtained by nonlinear regression of the sigmoid growth curves using the Graph Pad Prism 7.0 software.

\section{Ethics Statement}

$\mathrm{BALB} / \mathrm{c}$ mice were obtained from the Oswaldo Cruz Foundation (FIOCRUZ) animal facilities (Rio de Janeiro, Brazil). The mice were housed in a maximum of four per cage and kept in a conventional room $\left(23 \pm 2^{\circ} \mathrm{C}\right.$, relative humidity: $60 \%$, with $12 \mathrm{~h}$ light-dark cycles). The animals were provided with sterilized water and chow ad libitum. Studies in L. amazonensis and L. infantum-infected BALB/c mice were performed following the guidelines of the Guide for the Care and Use of Laboratory Animals of the Brazilian National Council of Animal Experimentation (COBEA). This study was approved by the Animal Ethics Committee of Oswaldo Cruz Institute (L26/2015).

\section{In vivo Studies}

\section{Murine model of the Cutaneous Leishmaniasis}

$\mathrm{BALB} / \mathrm{c}$ mice (four per group) were infected in the right ear with $2 \times 10^{6}$ promastigotes of L. amazonensis in the stationary phase of growth. Treatment was started seven days after infection. The dose was calculated based on the minimum recommended dose for humans $(50 \mathrm{mg} /$ day) and on an adaptation of the formula suggested by Reagan-Shaw et al., as follows: animal dose $(\mathrm{mg} / \mathrm{kg})$ $=($ human $\mathrm{Km} /$ animal $\mathrm{Km}) \times$ human dose $(\mathrm{mg} / \mathrm{kg})$, where mouse $\mathrm{Km}=3$, human $\mathrm{Km}=37$, and human weight $=70 \mathrm{~kg}$ (Reagan-Shaw et al., 2008). The animals were treated orally through an orogastric tube with a suspension of $8.8 \mathrm{mg}$ of spironolactone $/ \mathrm{kg} /$ day diluted in PBS containing 2\% DMSO or were treated intraperitoneally with $30 \mathrm{mg} \mathrm{SB}^{5+} / \mathrm{kg} /$ day of meglumine antimoniate; the control mice were given PBS containing 2\% DMSO. All animals were treated five times per week for 6 weeks. The disease's course was monitored by measuring the thickness of the infected ear with a caliper (Mitutoyo, São Paulo, Brazil) every 3 or 4 days for 49 days.

At the end of the experiment, the animals were euthanized by controlled $\mathrm{CO}_{2}$ inhalation. Ears containing the lesions were removed to analyze the parasite load by limiting dilution analysis (LDA), as described previously (da Cunha-Júnior et al., 2011). Tissues were macerated in Schneider medium containing 10\% FBS. The cell suspensions were then adjusted to $10 \mathrm{mg}$ tissue/mL in triplicate and were serially diluted 1:2 in 96-well plates, resulting in a final volume of $200 \mu \mathrm{L} /$ well. The cultures were observed for seven days using an inverted optical microscope to determine the lowest dilution containing parasites. The parasite load was expressed as the number of parasites/mg of tissue. A two-way ANOVA with a Bonferroni post-test was applied in the data analysis.

\section{Murine Model of Visceral Leishmaniasis}

$\mathrm{BALB} / \mathrm{c}$ mice were infected intraperitoneally with $1.0 \times 10^{8}$ promastigotes of $L$. infantum stationary phase. Seven days after infection, once the infection had already been established (Cunha-Júnior et al., 2016), treatment with spironolactone was introduced daily in three different doses of 4.4, 8.8, and $17.6 \mathrm{mg} / \mathrm{kg} /$ day. Control groups were treated with meglumine antimoniate $\left(28 \mathrm{mg} / \mathrm{kg} /\right.$ day of $\left.\mathrm{Sb}^{5+}\right)$ intraperitoneally. To determine the association between spironolactone and meglumine antimoniate, a fixed dose of meglumine antimoniate was used $\left(28 \mathrm{mg} / \mathrm{kg} /\right.$ day of $\left.\mathrm{Sb}^{5+}\right)$. After 23 days of treatment, the animals were euthanatized in a $\mathrm{CO}_{2}$ chamber, and the organs of interest (liver and spleen) were aseptically removed, weighed, and homogenized in Schneider's medium supplemented with $20 \%$ HIFCS. The parasitic load was estimated using a parasite LDA. Briefly, the resulting cell suspensions were serially diluted and evaluated by limiting dilution analysis after 7 days (Buffet et al., 1995). The number of parasites/organs was calculated as follows (geometric mean of titer from triplicate cultures $) \times($ common fraction of the homogenized organ added to the first well) $\times$ (weight of organ in $\mathrm{mg})$.

\section{RESULTS}

\section{In vitro Activity}

The direct antileishmanial activity of spironolactone was first evaluated by incubating $L$. amazonensis or $L$. infantum promastigotes with the drug for $72 \mathrm{~h}$. Spironolactone was a potent inhibitor of parasite growth, with an $\mathrm{IC}_{50}$ of 3.6 and $28.6 \mu \mathrm{M}$, respectively (Table 1). Next, we evaluated the spironolactone activity against the mammalian evolutive form of the parasite. Spironolactone was found to be active against intracellular amastigotes, with an $\mathrm{IC}_{50}$ of $1.8 \mu \mathrm{M}$ for $L$. amazonensis and $18.0 \mu \mathrm{M}$ for L. infantum (Table 1). The $\mathrm{CC}_{50}$ of spironolactone for peritoneal murine macrophages was $150 \mu \mathrm{M}$, demonstrating a selectivity index (SI) of 83.3 and 8.3 for L. amazonensis and L. infantum, respectively (Table 1). Then, we evaluated one of the spironolactone metabolites (potassium canrenoate) against Leishmania amazonensis. Interestingly, canrenoate, even at the highest concentration tested $(128 \mu \mathrm{M})$, was not active against promastigotes but showed an $\mathrm{IC}_{50}$ of $7.6 \mu \mathrm{M}$ in intracellular amastigotes, with less cytotoxicity $(>256 \mu \mathrm{M})$ in macrophages compared to spironolactone (Table 1).

\section{In vivo Efficacy}

After demonstrating the in vitro antileishmanial activity, we evaluated the efficacy on a murine experimental model of leishmaniasis using $L$. amazonensis or $L$. infantum. Spironolactone, orally delivered at $8.8 \mathrm{mg} / \mathrm{kg}$ five times per week (6 weeks-30 doses), was effective in controlling lesion development from the third week (Figure 2) and the parasite burden (insert Figure 2) in mice. There was no significant difference in either parameter evaluated between the treatment of spironolactone orally and meglumine antimoniate intraperitoneally.

Experimental visceral leishmaniasis was evaluated in $L$. infantum-infected BALB/c mice. Treatment using $17.6 \mathrm{mg} / \mathrm{kg} /$ day of spironolactone was effective in reducing the parasite load on the main affected organs (spleen and liver) (Figures 3A,B). However, it was less effective than the antimonial. To evaluate the benefit of the concomitant use of potassium-sparing diuretic with meglumine antimoniate, we associated the effective dose of meglumine antimoniate with the two lower doses of spironolactone $(4.4 \mathrm{mg} / \mathrm{kg} /$ day and $8.8 \mathrm{mg} / \mathrm{kg} /$ day $)$. The association promoted better control of the parasite load in the spleen 
TABLE 1 | IC 50 values for spironolactone and metabolite canrenoate on $L$. amazonensis and $L$. infantum promastigotes and intracellular amastigotes and $C C_{50}$ values for murine peritoneal macrophages and the selectivity index (SI).

\begin{tabular}{|c|c|c|c|c|c|c|c|}
\hline & \multirow{2}{*}{$\begin{array}{l}\text { Murine macrophage } \\
\qquad \mathrm{CC}_{50}(\mu \mathrm{M})\end{array}$} & \multicolumn{3}{|c|}{ L. amazonensis } & \multicolumn{3}{|c|}{ L. infantum } \\
\hline & & $\begin{array}{c}\text { Promastigote } I C_{50} \\
(\mu \mathrm{M})\end{array}$ & $\begin{array}{c}\text { Amastigote } I_{50} \\
(\mu \mathrm{M})\end{array}$ & SI & $\begin{array}{c}\text { Promastigote } I_{50} \\
(\mu \mathrm{M})\end{array}$ & $\begin{array}{c}\text { Amastigote } I C_{50} \\
(\mu \mathrm{M})\end{array}$ & SI \\
\hline Spironolactone & $150.0 \pm 3.4$ & $3.6 \pm 1.0$ & $1.8 \pm 0.7$ & 83.3 & $28.6 \pm 2.2$ & $18.0 \pm 1.1$ & 8.3 \\
\hline Canrenoate & $>256$ & $>128$ & $7.6 \pm 2.3$ & $>34.6$ & NT & NT & - \\
\hline
\end{tabular}

Values represent the mean \pm SE of three different experiments. NT-not tested.

compared with the antimonial alone $(98 \% \times 90 \%$ of reduction of the parasite load, respectively). In the liver, we noted a reduction of $97 \%$ in the group treated with meglumine antimoniate, while the association reduced $100 \%$ of the parasite load (Figures 3C,D).

\section{DISCUSSION}

Drug development is a long and expensive process, taking on average fifteen years of massive investment to generate a product. In leishmaniasis, there was a 60 -years gap between the release of pentavalent antimonials and the release of miltefosine (Dorlo et al., 2012; Sundar and Singh, 2016). The development of miltefosine, new formulations of conventional drugs, and combination treatments in recent years have represented a breakthrough for the chemotherapy of leishmaniasis. However, little impact has been observed in endemic areas, which can partly be explained by the high cost of these new alternatives, hindering their use in developing countries (Dorlo et al., 2012). Thus, repositioning drugs seems a suitable tool to search for new therapeutic options for the treatment of neglected diseases.
Here, we present the results of a project that aimed to study the antileishmanial activity of drugs currently used for other pathologies. Spironolactone, the most promising of these drugs, exhibited $\mathrm{IC}_{50}$ values of 1.8 and $18.0 \mu \mathrm{M}$ against the intracellular amastigotes of $L$. amazonensis and L. infantum, respectively (Table 1). Approximately $79 \%$ of the orally administered dose of spironolactone in humans is converted into canrenone, the most biologically active metabolite described for this drug (Gómez et al., 2005). This metabolite is hydrolyzed in its $\gamma$-lactone ring, generating canrenoate (soluble in water). After equilibrium, it reaches plasma concentrations like canrenone (Karim, 1978). The reverse also occurs; Karim et al. (1971) demonstrated that after intravenous administration of potassium canrenoate, lactonization of the hydroxy acid group of the canrenoate occurs, producing the $\gamma$-lactone ring of the canrenone. In $3 \mathrm{~h}$, equal concentrations of these two metabolites have already been found in plasma (Karim et al., 1971). We evaluated the activity of canrenoate and found that this metabolite demonstrates no activity against the promastigotes of L. amazonensis but remains active against intracellular amastigotes, although slightly less potent.

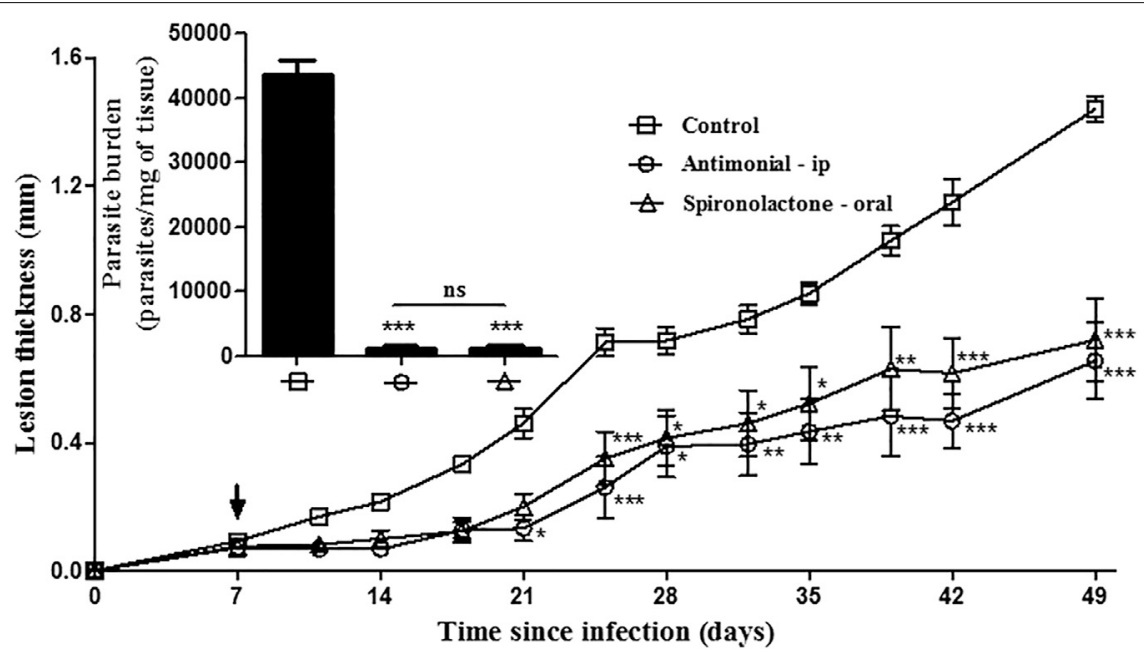

FIGURE 2 | Efficacy of oral spironolactone against murine cutaneous leishmaniasis. BALB/c mice were infected subcutaneously in the right ear with $2 \times 10^{6}$ promastigotes of $L$. amazonensis. All animals were treated five days $/$ week for six weeks. Spironolactone at $8.8 \mathrm{mg} / \mathrm{kg} / \mathrm{day}$ was diluted in PBS containing $2 \%$ DMSO and was given orally; meglumine antimoniate $\left(30 \mathrm{mg} / \mathrm{kg} /\right.$ day of the $\left.\mathrm{Sb}^{5+}\right)$ or PBS containing $2 \%$ DMSO was injected intraperitoneally in the right lower quadrant of the abdomen. The lesion development was monitored two times a week, measuring the infected ear with a caliper. At the end of the treatment, the animals were euthanized, and the parasite load was estimated by limiting dilution analysis (insert). Data are represented as the means \pm standard error of four animals per group. ${ }^{\star} p<0.05,{ }^{*} p<0.01$, and ${ }^{* \star *} p<0.001$ in treated groups $x$ control group. 

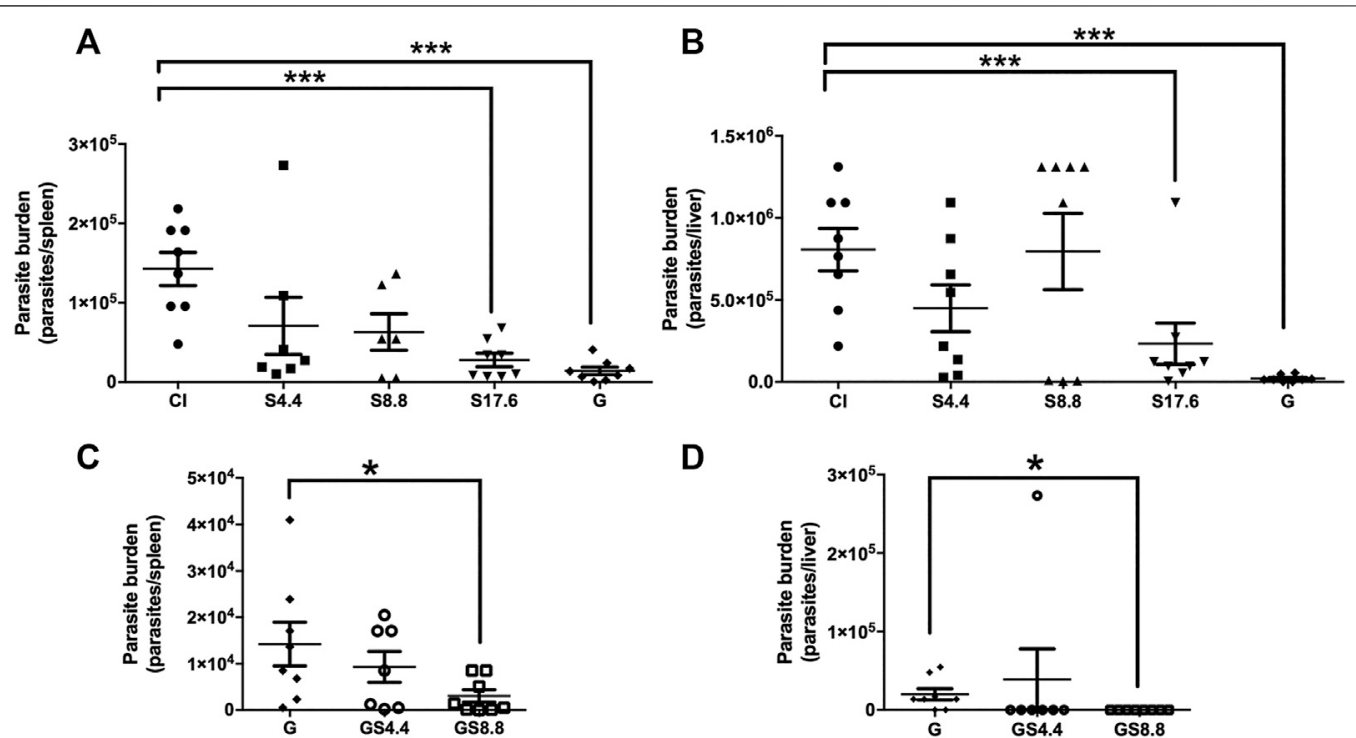

D

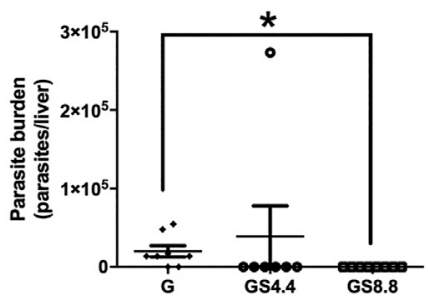

FIGURE 3 | Efficacy of oral spironolactone alone (A,B) and its association with meglumine antimoniate (C,D) in Experimental Visceral Leishmaniasis. BALB/c mice (8 per group) were infected intraperitoneally with $1.0 \times 10^{8}$ promastigotes of stationary phase $L$. infantum. Seven days after infection, the animals were treated with spironolactone in three different doses of 4.4, 8.8 , and $17.6 \mathrm{mg} / \mathrm{kg} /$ day along with meglumine antimoniate $\left(28 \mathrm{mg} / \mathrm{kg} /\right.$ day of Sb $\left.{ }^{5+}\right)$ by intraperitoneal route. The control group was treated with the vehicle via an oral route (PBS containing $2 \%$ DMSO). Regarding the association between spironolactone and meglumine antimoniate, a fixed dose of meglumine antimoniate $\left(28 \mathrm{mg} / \mathrm{kg} / \mathrm{day}\right.$ of $\left.\mathrm{Sb}^{5+}\right)$ was used with 4.4 or $8.8 \mathrm{mg} / \mathrm{kg} /$ day of spironolactone. After 23 days of treatment, the animals were euthanized in a $\mathrm{CO}_{2}$ chamber, and the spleen (panels $\mathbf{A}$ and $\mathbf{C}$ ) and liver (panels $\mathbf{B}$ and $\mathbf{D}$ ) were aseptically removed, weighed, and homogenized. The parasite load was estimated using the limiting dilution assay. Data are presented as means \pm standard error of 8 animals per group; ${ }^{*} p<0.05$ and ${ }^{* \star} p<0.001$; Cl: control infected; S: spironolactone; and G: meglumine antimoniate.

After demonstrating the in vitro selectivity of spironolactone, its ability to control the development of cutaneous leishmaniasis was evaluated. The infection of BALB/c mice with $L$. amazonensis is well established in the literature as a model of extreme susceptibility, with progressive swelling at the inoculation site accompanied by ulceration and metastasis (Neal and Hale, 1983). Oral treatment with spironolactone effectively controlled the development of the lesion and reduced the parasite load, with activity similar to that of meglumine antimoniate, which was administered intraperitoneally (Figure 2). Spironolactone treatment in the visceral leishmaniasis model showed efficacy, and the combination with meglumine antimoniate was promising. The combination of meglumine antimoniate with $8.8 \mathrm{mg} / \mathrm{kg} / \mathrm{day}$ of spironolactone was more effective than treatment with meglumine antimoniate alone. Some studies have shown that the use of meglumine antimoniate associated with other drugs is effective; for example, combinations with lapachone derivatives, azoles, amiodarone, and aminosidine sulfate have shown a greater effectiveness when compared to the use of meglumine antimoniate alone (Oliva et al., 1998; Anversa et al., 2017; Gonçalves-Oliveira et al., 2019).

Giannitrapani et al. (2009) described the case of a patient with visceral leishmaniasis who was previously diagnosed with cirrhosis. He was referred on admission for previous treatment with spironolactone and vitamin $\mathrm{K}$. The disease was advanced, and therapy with liposomal amphotericin B was instituted with good response. As it was not a controlled study, no conclusions can be drawn about how spironolactone influenced the development of the disease. In addition, data on dosage and treatment regimen were not mentioned. It is worth mentioning that spironolactone has contraindications for patients with anuria, acute renal failure, significant impairment of renal excretory function, or hyperkalemia. Thus, it should be used with caution in some cases, as described in the product monograph (Pfizer, 2015).

Spironolactone has a nucleus like other spirolactones, which are described as inhibitors of $17 \beta$-hydroxysteroid dehydrogenase $(17 \beta-H S D)$, an enzyme involved in the last stage of cholesterol biosynthesis (Poirier et al., 2001). In addition, spironolactone has also been implicated as an inhibitor of CYP90B1, which is responsible for the biosynthesis of brassinosteroid phytohormone in plants (Asami et al., 2004; Bajguz et al., 2020). Thus, a possible mechanism of antileishmania activity of this drug is interference in the sterol biosynthesis of the parasite. This pathway is considered essential since its pharmacological inhibition results in the death of the parasite (Roberts et al., 2003). However, specific experiments to evaluate this hypothesis must be carried out.

In conclusion, these results demonstrate a remarkable effect of spironolactone on murine cutaneous and visceral leishmaniasis. Additional studies are needed to determine the activity of spironolactone against other Leishmania species to optimize the therapeutic regimen and to determine its mechanism of action.

\section{DATA AVAILABILITY STATEMENT}

The raw data supporting the conclusion of this article will be made available by the authors, without undue reservation. 


\section{ETHICS STATEMENT}

Studies in L. amazonensis and L. infantum-infected BALB/c mice were performed following the guidelines of the Guide for the Care and Use of Laboratory Animals of the Brazilian National Council of Animal Experimentation (COBEA). The Animal Ethics Committee approved this study of Oswaldo Cruz Institute (L26/2015).

\section{AUTHOR CONTRIBUTIONS}

Conceptualization: EC-J and ET-S; Data curation: EC-J, VA-N, JF, and JP; Formal analysis: VA-N, ET-S, and EC-J; Investigation: VAN, JP, JF, EA-A, ET-S, and EC-J; Methodology: VA-N, JP, JF, ET-S, and EC-J; Writing - original draft: VA-N and EC-J; Writing - review \& editing, EA-A and ET-S.

\section{REFERENCES}

Agil, E. K. E. (2015). Treatment of leishmaniasis: a review and assessment of recent research. Curr. Pharm. Des. 21 (17), 2259-2275. doi:10.2174/ 1381612821666141231163053

Andrade-Neto, V. V., Cunha-Junior, E. F., Dos Santos Faioes, V., Pereira, T. M., Silva, R. L., Leon, L. L., et al. (2018). Leishmaniasis treatment: update of possibilities for drug repurposing. Front. Biosci. 23 (3), 967-996. doi:10.2741/4629

Anversa, L., Salles Tiburcio, M. G., Batista, L. R., Cuba, M. B., Nogueira Nascentes, G. A., Martins, T. Y., et al. (2017). Amiodarone and itraconazole improve the activity of pentavalent antimonial in the treatment of experimental cutaneous leishmaniasis. Int. J. Antimicrob. Agents 50 (2), 159-165. doi:10.1016/j. ijantimicag.2017.06.007

Asami, T., Oh, K., Jikumaru, Y., Shimada, Y., Kaneko, I., Nakano, T., et al. (2004). A mammalian steroid action inhibitor spironolactone retards plant growth by inhibition of brassinosteroid action and induces light-induced gene expression in the dark. J. Steroid Biochem. Mol. Biol. 91 (1-2), 41-47. doi:10.1016/j.jsbmb. 2004.01.011

Bajguz, A., Chmur, M., and Gruszka, D. (2020). Comprehensive overview of the brassinosteroid biosynthesis pathways: substrates, products, inhibitors, and connections. Front. Plant Sci. 11, 1034. doi:10.3389/fpls.2020.01034

Buffet, P. A., Sulahian, A., Garin, Y. J., Nassar, N., and Derouin, F. (1995). Culture microtitration: a sensitive method for quantifying Leishmania infantum in tissues of infected mice. Antimicrob. Agents Chemother. 39 (9), 2167-2168. doi:10.1128/aac.39.9.2167

Cunha-Júnior, E. F., Martins, T. M., Canto-Cavalheiro, M. M., Marques, P. R., Portari, E. A., Coelho, M. G. P., et al. (2016). Preclinical studies evaluating subacute toxicity and therapeutic efficacy of LQB-118 in experimental visceral leishmaniasis. Antimicrob. Agents Chemother. 60 (6), 3794-3801. doi:10.1128/ AAC.01787-15

da Cunha-Júnior, E. F., Pacienza-Lima, W., Ribeiro, G. A., Netto, C. D., CantoCavalheiro, M. M. d., da Silva, A. J. M., et al. (2011). Effectiveness of the local or oral delivery of the novel naphthopterocarpanquinone LQB-118 against cutaneous leishmaniasis. J. Antimicrob. Chemother. 66 (7), 1555-1559. doi:10.1093/jac/dkr158

de Morais-Teixeira, E., Rabello, A., and Aguiar, M. M. G. (2019). In vitro activity and in vivo efficacy of fexinidazole against New World Leishmania species. J. Antimicrob. Chemother. 74 (8), 2318-2325. doi:10.1093/jac/dkz172

Dorlo, T. P. C., Balasegaram, M., Beijnen, J. H., and de Vries, P. J. (2012). Miltefosine: a review of its pharmacology and therapeutic efficacy in the treatment of leishmaniasis. J. Antimicrob. Chemother. 67 (11), 2576-2597. doi:10.1093/jac/dks275

Faiões, V. d. S., dos, S., da Frota, L. C. R. M., Cunha-Junior, E. F., Barcellos, J. C. F., Da Silva, T., et al. (2018). Second-generation pterocarpanquinones: synthesis and antileishmanial activity. J. Venom Anim. Toxins Incl Trop. Dis. 24 (1). doi:10.1186/s40409-018-0174-7

\section{FUNDING}

This work was supported by Fundação Carlos Chagas Filho de Amparo à Pesquisa do Estado do Rio de Janeiro (FAPERJ) through fellowships E-26/202.348/2017 awarded to VVAN and E-26/202.371/2019 awarded to EFCJ (pós-doutorado nota 10), grant E-26/202.918/2018 awarded to ECTS (Cientista do Nosso Estado), Conselho Nacional de Desenvolvimento Científico e Tecnológico $(\mathrm{CNPq})$ grant 438858/2018-2 awarded to EFCJ, and Fundação Oswaldo Cruz (FIOCRUZ). E.E.A-A. was the recipient of a research fellowship from Conselho Nacional de Desenvolvimento Científico e Tecnológico (CNPq). J.D.F.I. was a recipient of a postdoctoral fellowship from Fundação Oswaldo Cruz (FIOCRUZ). All funders are governmental non-profit foundations that support research in Brazil.

GBD 2015 DALYs and HALE Collaborators (2016). Global, regional, and national disability-adjusted life-years (DALYs) for 315 diseases and injuries and healthy life expectancy (HALE), 1990-2015: a systematic analysis for the Global Burden of Disease Study 2015. Lancet 388 (10053), 1603-1658. doi:10.1016/S0140 6736(16)31460-X

Giannitrapani, L., Soresi, M., La Spada, E., Tripodo, C., and Montalto, G. (2009). Progressive visceral leishmaniasis misdiagnosed as cirrhosis of the liver: a case report. J. Med. Case Rep. 3 (1), 7265-7274. doi:10.4076/17521947-3-7265

Gómez, R., Núñez, L., Caballero, R., Vaquero, M., Tamargo, J., and Delpón, E. (2005). Spironolactone and its main metabolite canrenoic acid block hKv1.5, Kv4.3 and Kv7.1+minK channels. Br. J. Pharmacol. 146 (1), 146-161. doi:10. 1038/sj.bjp.0706302

Gonçalves-Oliveira, L. F., Souza-Silva, F., de Castro Côrtes, L. M., Veloso, L. B., Santini Pereira, B. A., Cysne-Finkelstein, L., et al. (2019). The combination therapy of meglumine antimoniate and oxiranes (epoxy- $\alpha$-lapachone and epoxymethyl-lawsone) enhance the leishmanicidal effect in mice infected by Leishmania (Leishmania) amazonensis. Int. J. Parasitol. Drugs Drug Resist. 10, 101-108. doi:10.1016/j.ijpddr.2019.08.002

Karim, A., Ranney, R. E., and Maibach, H. I. (1971). Pharmacokinetic and metabolic fate of potassium canrenoate (SC-14266) in man. J. Pharm. Sci. 60 (5), 708-715. doi:10.1002/jps.2600600510

Karim, A. (1978). Spironolactone: disposition, metabolism, pharmacodynamics, and bioavailability. Drug Metab. Rev. 8 (1), 151-188. doi:10.3109/ 03602537808993782

Neal, R. A., and Hale, C. (1983). A comparative study of susceptibility of inbred and outbred mouse strains compared with hamsters to infection with New World cutaneous leishmaniases. Parasitology 87 (1), 7-13. doi:10.1017/ s0031182000052379

Oliva, G., Gradoni, L., Cortese, L., Orsini, S., Ciaramella, P., Scalone, A., et al. (1998). Comparative efficacy of meglumine antimoniate and aminosidine sulphate, alone or in combination, in canine leishmaniasis. Ann. Trop. Med. Parasitol. 92 (2), 165-171. doi:10.1080/0003498986000310.1080/00034983. 1998.11813276

Pfizer (2015). Aldactone_PM_E_178267_23Jul2015.pdf. https://www.pfizer.ca/. Available at: https://www.pfizer.ca/sites/default/files/201712/Aldactone_PM_ E_178267_23Jul2015.pdf (Accessed February 16, 2021).

Poirier, D., Bydal, P., Tremblay, M. R., Sam, K.-M., and Luu-The, V. (2001). Inhibitors of type II $17 \beta$-hydroxysteroid dehydrogenase. Mol. Cell Endocrinol. $171(1,2), 119-128$. doi:10.1016/s0303-7207(00)00427-5

Reagan-Shaw, S., Nihal, M., and Ahmad, N. (2008). Dose translation from animal to human studies revisited. FASEB J. 22 (3), 659-661. doi:10.1096/fj.079574LSF

Roberts, C. W., McLeod, R., Rice, D. W., Ginger, M., Chance, M. L., and Goad, L. J. (2003). Fatty acid and sterol metabolism: potential antimicrobial targets in apicomplexan and trypanosomatid parasitic protozoa. Mol. Biochem. Parasitol. 126 (2), 129-142. doi:10.1016/s0166-6851(02)00280-3 
Sundar, S., and Singh, A. (2016). Recent developments and future prospects in the treatment of visceral leishmaniasis. Ther. Adv. Infect. 3 (3-4), 98-109. doi:10. $1177 / 2049936116646063$

Sunyoto, T., Boelaert, M., and Meheus, F. (2019). Understanding the economic impact of leishmaniasis on households in endemic countries: a systematic review. Expert Rev. Anti-infective Ther. 17 (1), 57-69. doi:10.1080/14787210. 2019.1555471

WHO Control of Neglected Tropical Diseases (2020). Global leishmaniasis surveillance, 2017-2018, and first report on 5 additional indicators. Available at: https://www. who.int/publications/i/item/who-wer9525 (Accessed November 30, 2020).

Wile, D. (2012). Diuretics: a review. Ann. Clin. Biochem. 49 (Pt 5), 419-431. doi:10. 1258/acb.2011.011281

Wyllie, S., Patterson, S., Stojanovski, L., Simeons, F. R. C., Norval, S., Kime, R., et al. (2012). The anti-trypanosome drug fexinidazole shows potential for treating visceral leishmaniasis. Sci. Transl. Med. 4 (119), 119re1. doi:10.1126/ scitranslmed. 3003326

Conflict of Interest: The authors declare that the research was conducted in the absence of any commercial or financial relationships that could be construed as a potential conflict of interest.

Copyright (C) 2021 Andrade-Neto, da Silva Pacheco, Inácio, Almeida-Amaral, Torres-Santos and Cunha-Junior. This is an open-access article distributed under the terms of the Creative Commons Attribution License (CC BY). The use, distribution or reproduction in other forums is permitted, provided the original author(s) and the copyright owner(s) are credited and that the original publication in this journal is cited, in accordance with accepted academic practice. No use, distribution or reproduction is permitted which does not comply with these terms. 